\title{
When you hear hoofbeats, think of horses and zebras: a 58-year-old man with chest pain and palpitations
}

\author{
Bartosz Hudzik · Janusz Szkodzinski • \\ Aleksandra Wozniak • Alicja Nowowiejska-Wiewiora • \\ Lech Polonski
}

Received: 4 December 2010/ Accepted: 17 February 2011/Published online: 3 March 2011

(C) SIMI 2011

\section{Case presentation and primary diagnosis}

Dr. Szkodzinski, Dr. Nowowiejska-Wiewiora: A 58-yearold man presented to the emergency department (ED) with chest pain and palpitations of $2 \mathrm{~h}$ duration as well as a rapid heart rate (approximately 170 beats $/ \mathrm{min}$ ) and dizziness. The patient reported episodic palpitations within the prior 12 months. His past medical history was negative for prior surgeries, medications or any drug allergies. On admission, the patient was normotensive, normocardic and afebrile. Physical examination was unremarkable. An electrocardiogram (ECG) showed a normal sinus rhythm with slight ST-segment elevation in precordial leads V1 and V2, and a rsr' pattern in V1 (Fig. 1a). Laboratory tests revealed elevated cardiac marker CK-MB mass $20 \mathrm{ng} / \mathrm{mL}$ (upper limit of normal $5 \mathrm{ng} / \mathrm{mL}$ ) and troponin $\mathrm{T} 0.4 \mathrm{ng} / \mathrm{mL}$ (upper limit of normal $0.1 \mathrm{ng} / \mathrm{mL}$ ). Based on the clinical presentation, elevated cardiac markers and ECG findings, a primary diagnosis of ST-segment elevation myocardial infarction (STEMI) was made. The patient received $5,000 \mathrm{U}$ of unfractionated heparin IV, $300 \mathrm{mg}$ of aspirin and $600 \mathrm{mg}$ of clopidogrel, and was transferred to catheterization laboratory.

\footnotetext{
B. Hudzik $(\bowtie) \cdot$ J. Szkodzinski · A. Nowowiejska-Wiewiora · L. Polonski

3rd Department of Cardiology, Silesian Center for Heart Disease, Medical University of Silesia, Szpitalna 2, 41-800 Zabrze, Poland

e-mail: bartekh@mp.pl
}

\author{
A. Wozniak \\ Department of Cardiology, Congenital Heart Disease \\ and Electrotherapy, Silesian Center for Heart Disease, \\ Medical University of Silesia, Zabrze, Poland
}

\section{Final diagnosis}

Dr. Hudzik, Dr. Wozniak: Coronary angiography showed normal coronary arteries. The ECG tracing normalized after the procedure (Fig. 1b). Echocardiography revealed normal left and right ventricle functions (left ventricular ejection fraction 60\%) with no structural heart disease. Inflammatory states were excluded based on negative inflammation markers [high-sensitivity C-reactive protein $0.9 \mathrm{mg} / \mathrm{L}$, erythrocyte sedimentation rate $6 \mathrm{~mm} / \mathrm{h}$, normal leukocyte count $6.7\left(10^{3} / \mathrm{mm}^{3}\right)$ ], serum procalcitonin was undetectable $(<0.05 \mathrm{ng} / \mathrm{mL})$. 24-h electrocardiographic (Holter) monitoring test was performed, which revealed numerous ventricular extrasystoles with multiple episodes of bigeminy, trigeminy and one episode of non-sustained ventricular tachycardia. Given the history of palpitations,

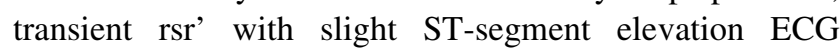
pattern and ventricular dysrhythmia, the possibility of a Brugada syndrome was raised. An ajmaline challenge test was performed (1 mg/kg over $5 \mathrm{~min}$, IV) (Fig. 2a-f) [1]. Ajmaline infusion unmasked a type 1 Brugadasyndrome electrocardiographic pattern-a morphology of the QRS complex resembling a right bundle branch block with a coved type ST-segment elevation (with a $2.5 \mathrm{~mm}$ J-point elevation in V1 and $3.0 \mathrm{~mm}$ J-point elevation in V2) and a gradually descending ST-segment and a negative T-wave (Fig. 2f). These changes dissolved $15 \mathrm{~min}$ after cessation of the ajmaline infusion. T-wave alternans (TWA) was positive indicating that the patient was at increased risk of sudden cardiac death (SCD) (Fig. 3). Although our diagnostic strategy (the use of $\mathrm{T}$-wave alternans) was probably somewhat outside the present guidelines, the latest reports indicate that TWA is associated with a high risk of clinical VF in patients with a Brugada syndrome [2,3]. 
Fig. 1 Electrocardiogram on admission (a) and after coronary angiography (b)

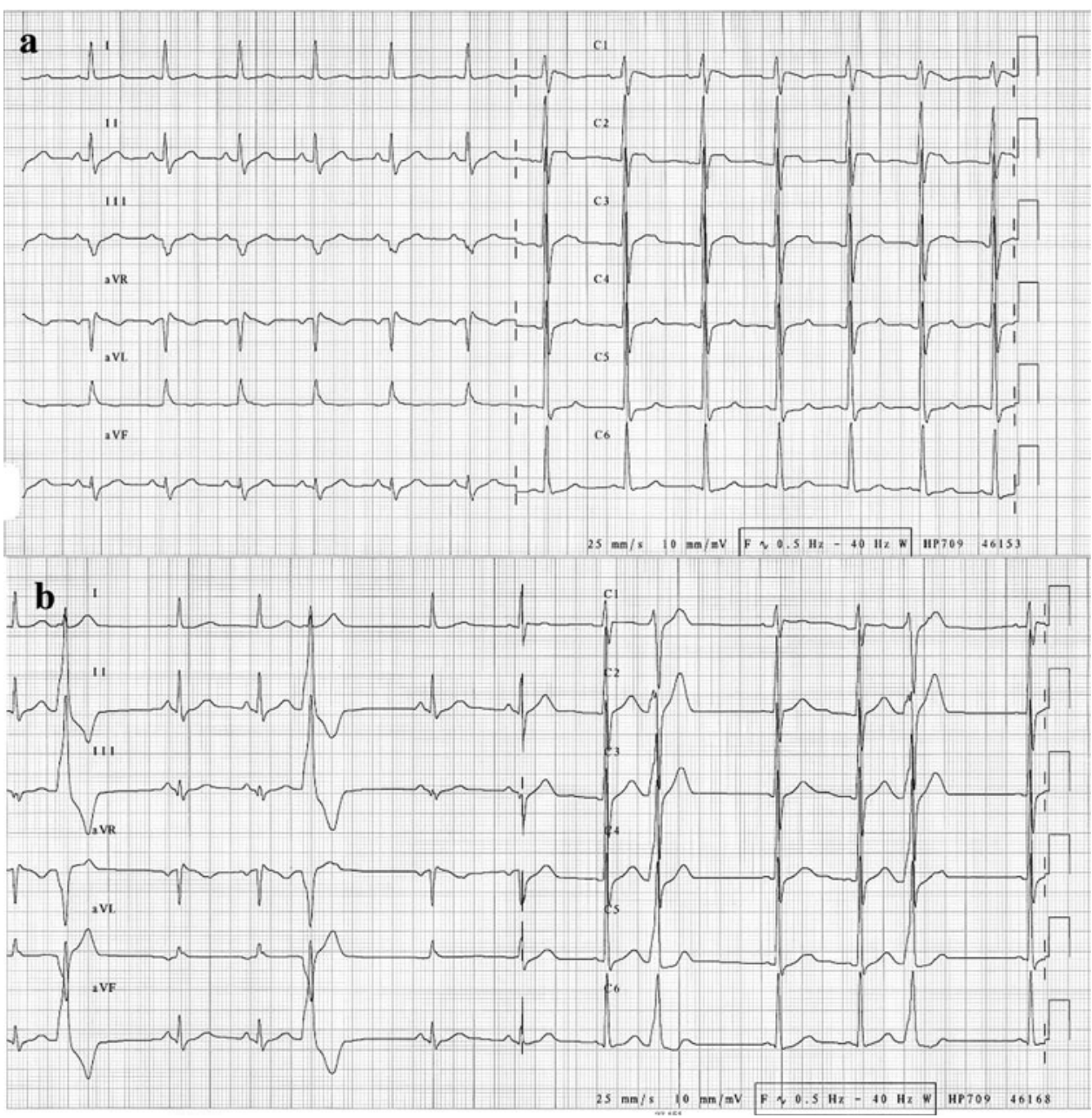

\section{Treatment}

Dr. Hudzik, Dr. Szkodzinski: We presumed that positive troponin and CK-MB were associated with the reported palpitations with a rapid heart rate, which could have resulted from a sustained ventricular tachycardia, which, in turn, could have led to the increase in serum cardiac markers. We ruled out myocarditis as the cause of the presented symptoms, given the negative inflammatory markers, preserved left ventricular systolic function, no pericardial effusion, the dynamics of ECG changes and no prior history of infection or febrile state. Therefore, we did not perform contrast-enhanced magnetic resonance imaging to exclude myocarditis [4].

Given the diagnosis, ventricular dysrhythmia and a positive TWA, the patient underwent a successful placement of an implantable cardioverter-defibrillator (ICD). The patient was discharged and remained well during 6-month follow-up.

\section{Discussion}

Dr. Hudzik, Dr. Szkodzinski, Prof. Polonski: During medical training, students and residents are being taught a quintessential maxim of clinical medicine- "When you hear hoofbeats, think of horses, not zebras". Common diseases are what physicians should expect to encounter. Unfortunately, in a world of horses, the hoofbeats of zebras too often go unrecognized or misdiagnosed. The diagnosis of Brugada syndrome may be difficult and somewhat tricky, given that a wide spectrum of diseases can be associated with ST-segment elevation [5]. These include: acute myocardial infarction, variant angina, pericarditis, myocarditis, early repolarization syndrome, and aortic dissection. Brugada-type ECG changes may be also elicited by other conditions: in some patients during febrile states and in those who are under the influence of cocaine and pharmaceutical drugs that have a sodium channel-blocking effect, such as antidysrhythmics, anesthetics, and tricyclic 
Fig. 2 Electrocardiogram (ECG) during administration of ajmaline (50 $\mathrm{mg}$ in $5 \mathrm{~min}$ ). Note the progressive appearance of the ST-segment elevation in V1-V2. a Baseline ECG; ajmaline infusion: b $1^{\prime}$ ECG; c $2^{\prime}$ ECG; d $3^{\prime}$ ECG; e 4' ECG; f $5^{\prime} \mathrm{ECG}$

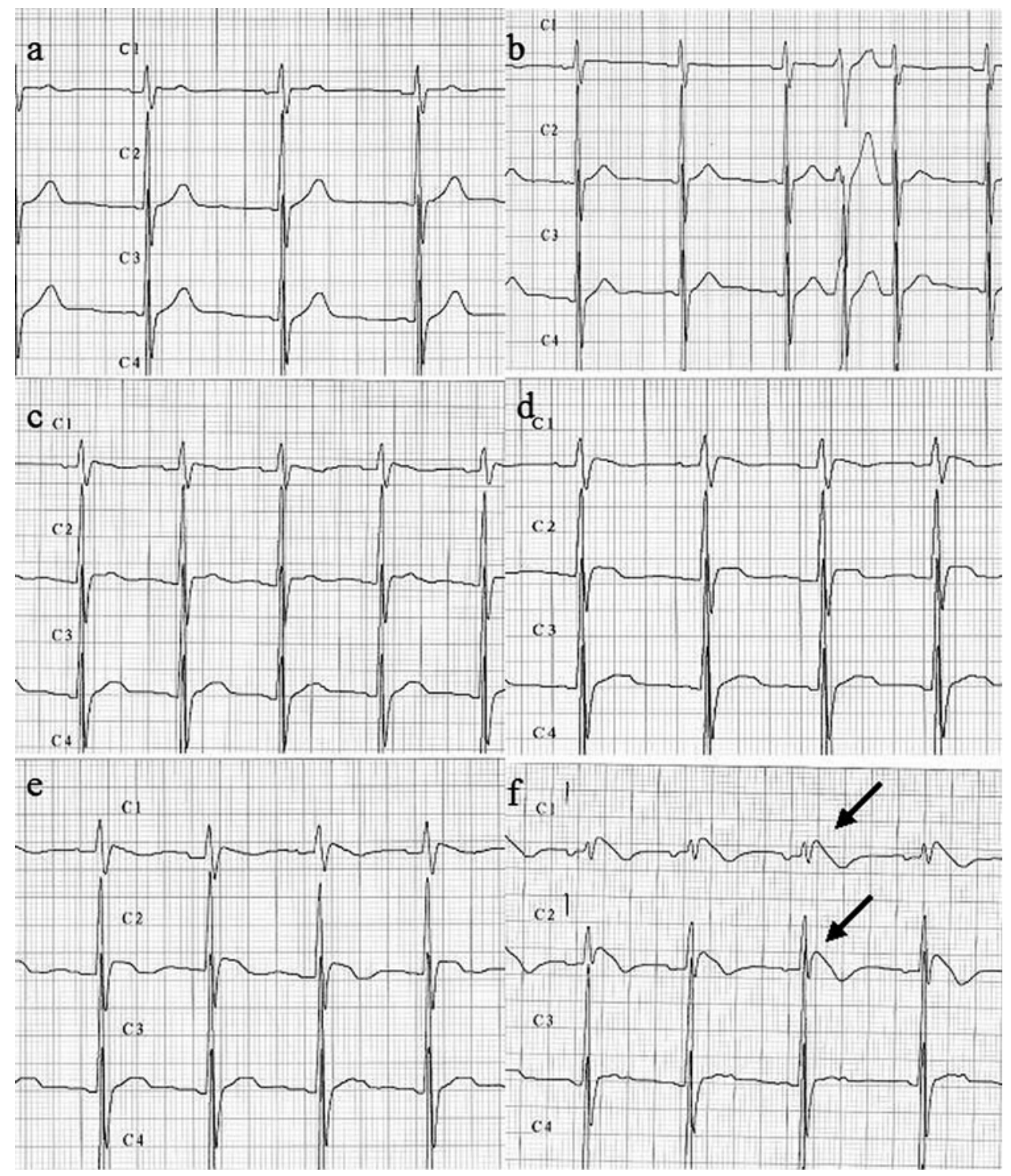

antidepressants (although the clinical meaning and the risk of dysrhythmias induced by this pattern are unknown) [6]. A differential diagnosis is at times difficult, particularly when the degree of ST-segment elevation is relatively small [1]. Gu et al. [7] examined 820 patients with suspected STEMI and found 19 patients with conditions mimicking STEMI (final diagnosis other than acute myocardial infarction). They report one patient (5\%) with a primary diagnosis of STEMI who was finally diagnosed with a Brugada syndrome, and an ICD was implanted. Similar cases have been reported previously [8, 9].

Timely institution of reperfusion therapy is essential in the treatment of STEMI [10, 11]. Therefore, available time most often does not allow for a solid differential diagnosis. We should be especially vigilant in the settings of suspected STEMI and normal coronary arteries on coronary angiography.
Meanwhile, ECG changes are the hallmark of the Brugada syndrome, which consist of (a) an electrocardiographic pattern with a static or transient ST-segment elevation (Table 1); (b) a structurally normal heart and (c) a predisposition toward ventricular tachyarrhythmias leading to syncope or SCD [12, 13]. The diagnosis of Brugada syndrome can be made if a type 1 ECG pattern occurs spontaneously or after pharmacological provocative tests [14]. When type 2 or 3 patterns are observed, a conversion to type 1 pattern must occur during sodium channel blocker (e.g., procainamide, ajmaline, flecainide) administration to make a diagnosis of Brugada syndrome. The diagnosis of Brugada syndrome can be made if type $1 \mathrm{ECG}$ pattern is accompanied by at least one of the following clinical situation [4]:

- documented VF,

- documented polymorphic VT, 
Fig. 3 T-wave alternans (black arrows positive alternans, asterisk artefacts caused by numerous ventricular extrasystoles). $H R$ heart rate; $B P M$ beats per minute; Resp. respiratory rate; $X, Y, Z$ frank leads; $R R$ blood pressure (not measured in this report); $V-V 6$ precordial leads

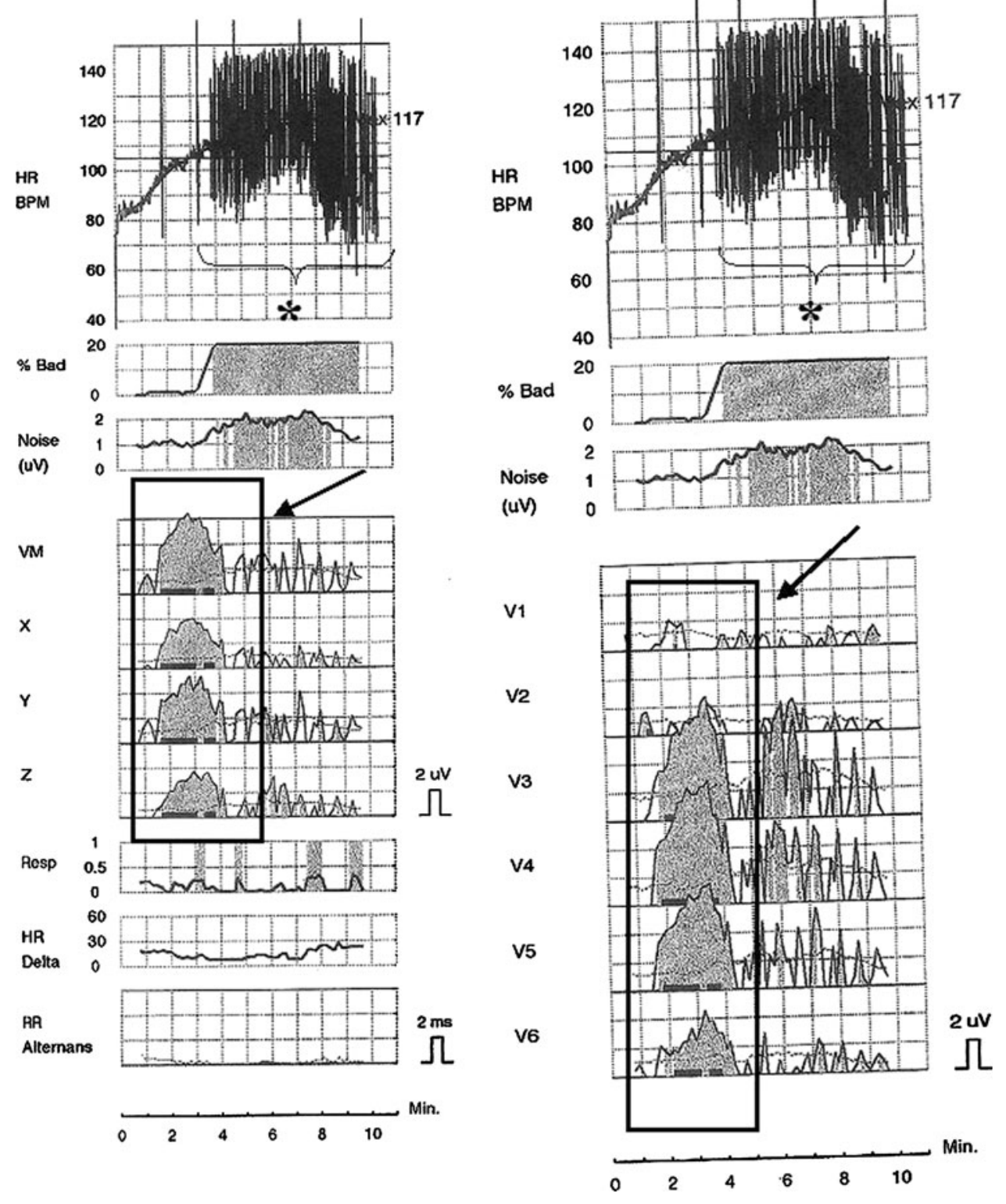

Table 1 Electrocardiographic types of ST-segment elevation in leads $\mathrm{V} 1-\mathrm{V} 3$ in Brugada syndrome

\begin{tabular}{ll}
\hline Type 1 & J-point or ST-segment elevation $>2 \mathrm{~mm}$ \\
& at its peak followed by a negative \\
& T-wave (cove-type appearance) \\
Type 2 & J-point amplitude $>2 \mathrm{~mm}$ giving rise \\
& to a downsloping ST-segment elevation $\geq 1 \mathrm{~mm}$ \\
Type 3 & above baseline ("saddle back" appearance) \\
& to a downsloping ST-segment elevation $<1 \mathrm{~mm}$ \\
& above baseline ("saddle back" appearance) \\
\hline
\end{tabular}

- inducible ventricular dysrhythmias during electrophysiological study (EPS),

- syncope,

- family history of SCD at $<45$ years of age

- ECG type 1 pattern in other family members.
A proper diagnosis is crucial given the life-threatening nature of the disease. Up to $27 \%$ of patients with a Brugada syndrome are at risk of developing ventricular tachycardia/ fibrillation or SCD. ICD placement is currently the only treatment of proven efficacy for the management of the Brugada syndrome.

It is prudent to search for a Brugada syndrome when classical ECG findings are absent, but the patient has symptoms of dysrhythmia and normal coronary arteries.

Conflict of interest None.

\section{References}

1. Antzelevitch C, Brugada P, Borggrefe M, Brugada J, Brugada R, Corrado D, Gussak I, LeMarec H, Nademanee K, Perez Riera 
AR, Shimizu W, Schulze-Bahr E, Tan H, Wilde A (2005) Brugada syndrome: report of the second consensus conference: endorsed by the Heart Rhythm Society and the European Heart Rhythm Association. Circulation 111:659-670

2. Morita H, Zipes DP, Wu J (2009) Brugada syndrome: insights of ST elevation, arrhythmogenicity, and risk stratification from experimental observations. Heart Rhythm 6:S34-S43

3. Tada T, Kusano KF, Nagase S, Banba K, Miura D, Nishii N, Watanabe A, Nakamura K, Morita H, Ohe T (2008) Clinical significance of macroscopic $\mathrm{T}$-wave alternans after sodium channel blocker administration in patients with Brugada syndrome. J Cardiovasc Electrophysiol 19:56-61

4. Camastra GS, Cacciotti L, Semeraro R, Marconi F, Sbarbati S, Danti M, Della Sala S, Ansalone G (2009) Contrast-enhanced MRI to recognize myocarditis with STEMI presentation. Intern Emerg Med 4:183-185

5. Wang K, Asinger RW, Marriott HJ (2003) ST-segment elevation in conditions other than acute myocardial infarction. $\mathrm{N}$ Engl $\mathrm{J}$ Med 349:2128-2135

6. Junttila MJ, Gonzalez M, Lizotte E, Benito B, Vernooy K, Sarkozy A, Huikuri HV, Brugada P, Brugada J, Brugada R (2008) Induced Brugada-type electrocardiogram, a sign for imminent malignant arrhythmias. Circulation 117:1890-1893

7. Gu YL, Svilaas T, van der Horst IC, Zijlstra F (2008) Conditions mimicking acute ST-segment elevation myocardial infarction in patients referred for primary percutaneous coronary intervention. Neth Heart J16:325-331

8. Gallahue FE, Uzgiris R, Burke R, Abrahams W (2009) Brugada syndrome presenting as an "acute myocardial infarction". J Emerg Med 37:15-20

9. Sajeev CG, Vinayakumar D, Venugopal K (2005) Brugada syndrome simulating acute myocardial infarction. Int $\mathrm{J}$ Cardiol 99:155-156

10. Balzi D, Barchielli A, Santoro GM, Carrabba N, Buiatti E, Giglioli C, Valente S, Baldereschi G, Del Bianco L, Monami M, Gensini GF, Marchionni N (2008) Management of acute myocardial infarction in the real world: a summary report from The Ami-Florence Italian Registry. Intern Emerg Med 3:109-115

11. Melandri G, Semprini F, Nanni S, Calabrese D, Vagnarelli F, Branzi A (2008) STEMI management: trials, registries, and the real world. Intern Emerg Med 3:83-84

12. Brugada P, Brugada J, Brugada R (2002) The Brugada syndrome. Card Electrophysiol Rev 6:45-48

13. Mattu A, Rogers RL, Kim H, Perron AD, Brady WJ (2003) The Brugada syndrome. Am J Emerg Med 21:146-151

14. Wilde AA, Antzelevitch C, Borggrefe M, Brugada J, Brugada R, Brugada P, Corrado D, Hauer RN, Kass RS, Nademanee K, Priori SG, Towbin JA (2002) Proposed diagnostic criteria for the Brugada syndrome. Eur Heart J23:1648-1654 